\title{
Geotechnical properties of the Quaternary sediments in Shanghai
}

\author{
A. Dassargues, P. Biver and A. Monjoie \\ Laboratory of Engineering Geology, Hydrogeology and Geophysical Prospecting. \\ University of Liège, Liège, Belgitum
}

(Received July 6, 1989; accepted after revision February 26, 1990)

\begin{abstract}
Dassargues, A., Biver, P. and Monjoie, A., 1991. Geotechnical properties of the Quaternary sediments in Shanghai. Eng. Geol., 31: 71-90.
\end{abstract}

The subsoil of Shanghai is composed of Quaternary sediments of the Yangtse River estuary. The center of the city has undergone a man-induced subsidence due to water pumping in the confined multi-aquifer system located in these sediments. Together with a sedimentological study of the post-Pleistocene conditions of deposition and accumulation, an accurate geotechnical study has been completed on the basis of all the available data from identification, oedometer and triaxial tests. Size analysis, X-ray analysis, compressibility characteristics, void ratio, preconsolidation pressures, permeabilities are considered taking into account the sedimentary sequence. Some relations between parameters are deduced and the hydrodynamic parameters are related to compaction parameters in order to predict their coupled and non-linear effects on the subsidence phenomena.

Conclusions consist in the determination of the zones where different sensitivities to compaction are evaluated in these Quaternary formations.

\section{INTRODUCTION}

As a result of groundwater withdrawal, land subsidence occurred severely in Shanghai with an approximative total value of $2.5 \mathrm{~m}$ since 1920 and a maximum annual rate of $98 \mathrm{~mm}$ between 1956 and 1959. Since 1962, the recharge of the main aquifer during winters has contributed to decelerate the phenomena but a residual consolidation of about 2 to $3 \mathrm{~mm}$ a year is still recorded.

The subsoil of Shanghai is composed of loose sediments which consist of clay, loam, silt and sand, the different deposits being the final result of the variation from an estuarine to fluviatile sedimentation process.

The study reported herein has been undertaken to examine the engineering geology properties of the upper $70 \mathrm{~m}$ layers of these Quaternary deposits, in order to prepare all the data needed for a mathematical model computing the land subsidence.

The sedimentological study of the Quaternary deposits has been achieved by Dr. C. Baeteman of the Belgian Geological Survey (Baeteman, 1989) and the X-Ray analysis by Prof. Thorez (University of Liège). The results of the bore-holes, CPT, 
identification tests and low-pressure oedometer tests have been provided by the Shanghai Geological Center and the other tests (especially high-pressure oedometers) have been performed in our Laboratory of Engineering Geology, Hydrogeology and Geophysical Prospecting (University of Liège).

\section{STUDY AREA}

The city of Shanghai is situated at proximately $70 \mathrm{~km}$ from the sea shore, in the large coastal plain limited by the East China Sea and the Yangtse River. However, this area has been designated as the "Yangtse River Delta", and all the features and characteristics of the sediments show the physiographic evolution of the estuarine system.

From a lithological point of view, the subsoil of these coastal lowlands consists of a thick (about $300 \mathrm{~m}$ ) sequence of low consolidated sediments, sensitive to compaction. Since 1920, in the central area of Shanghai, the main withdrawal of water came from the second aquifer. The top of this sandy layer is situated between 60 and $80 \mathrm{~m}$ of depth, that is why the main part of the subsidence is supposed to be due to the compaction of the compressible layers located between this aquifer and the surface.

The study area is the central zone of Shanghai (Fig.1) and by this fact, every supplementary in-situ investigation was complicated by the lack of place in such a highly populated city (population density more than 50000 inhabitants $/ \mathrm{km}^{2}$ ).

\section{ANALYSIS OF THE QUATERNARY SEDIMENTS}

The correlations are based on observations from borings and on interpretations of the cone penetration tests (CPT) and the nuclear well-logging (gamma-ray, gammagamma, neutron-neutron). Cross-sections covering the entire studied area have been drawn (Baeteman, 1989).

The Yangtse (Changjiang) coastal plain is an area where coastal sedimentary processes have dominated in the entire Late Quaternary history. The shifting back and forwards of the estuary formed by the river has left complex deposits. The estuarine conditions of sedimentation have reoccupied the same places during various transgressions leaving similar deposited lithofacies.

In the studied zone, the Upper Pleistocene deposits (of the upper $70 \mathrm{~m}$ ) consist in a sequence typical of a transition from an estuarine environment to a fluvial one.

The top of the sandy layer usually called second aquifer, is situated at a depth of about $70 \mathrm{~m}$, this layer being representative of estuarine conditions. In the lithological sequence, it is overlain (Fig.2) by a clayey layer, sensitive to compaction and with features of subtidal and intertidal conditions. This unit is usually named third compressible layer. The latest unit formed in the estuarine environment is again composed of sand deposits gradually replaced by fluvial silt and sand, typical of the beginning of a fluvial phase. All these sand and silty sand deposits compose the unit usually named first aquifer. In some zones, the first and second aquifers are joined especially in the southern part of the study area.

The final stage of the fluvial sequence is completed during low sea-level stand, by the formation of a clay flood-basin. This layer of clay, known as Dark Green Stiff Clay $(D G S C)$ is characterized by a high bearing capacity caused by its previous consolidation by dewatering. 


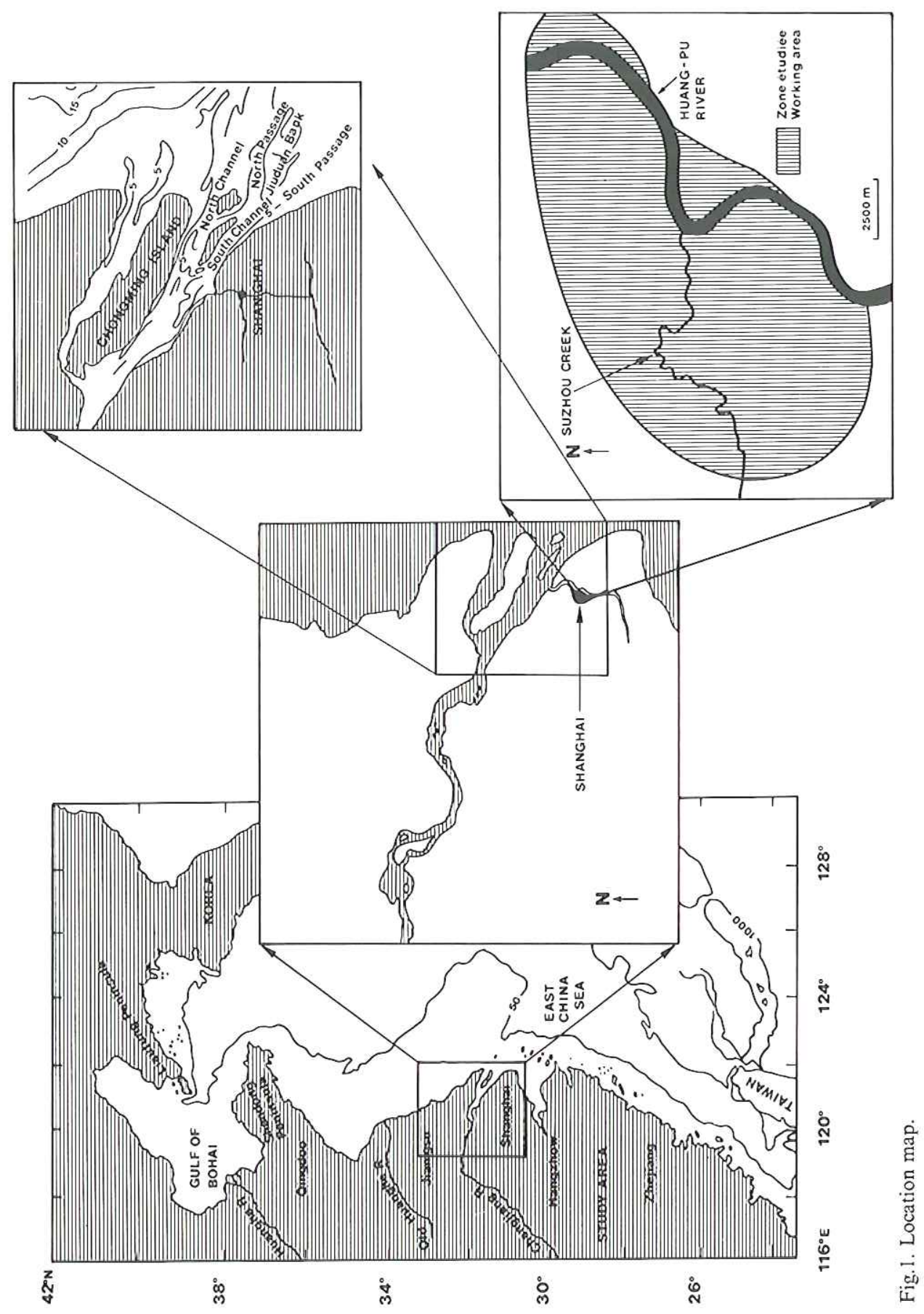




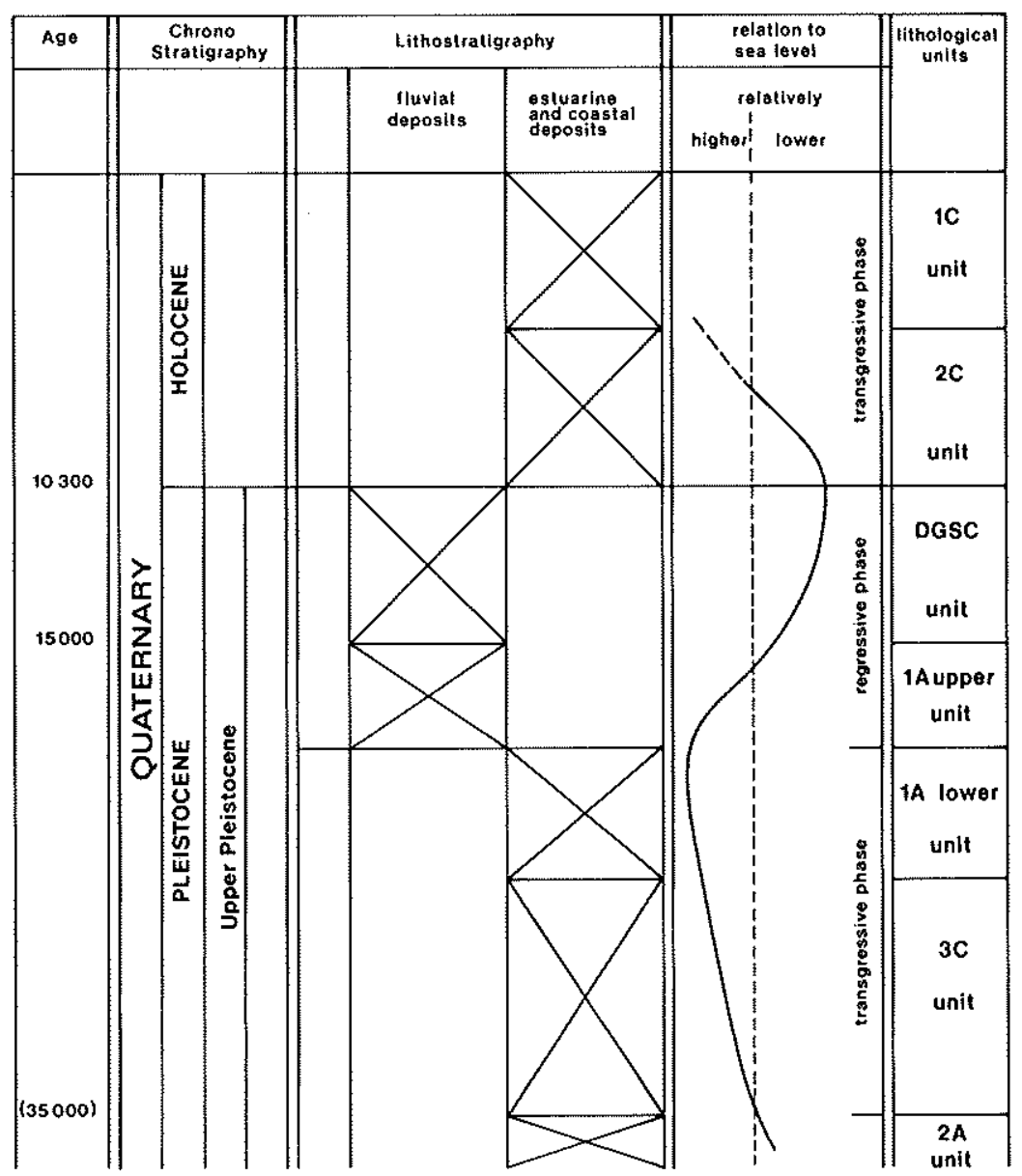

Fig.2. Geological sequence (Baeteman, 1989).

Two reasons can explain the absence in some zones of the DGSC layer: (1) during the last step of the river avulsion process, a last flood-basin adjacent to its new position had no time enough to be built; (2) at the beginning of the post-glacial period (Holocene) the general climatic amelioration led to an erosion process in its own flood basin.

In the Holocene period, as the estuarine environment again prevailed, silty clay sediments have been deposited: (1) supratidal deposits corresponding to a layer usually called second compressible; and (2) tidal flats deposits corresponding to a layer named first compressible.

Both of them are very sensitive to compaction and consolidation, with very high mud supply from the rivers.

Fig. 3 represents one of the cross-sections in the studied zone showing the relative heterogeneity of the deposits and the absence of the DGSC layer in some places. 


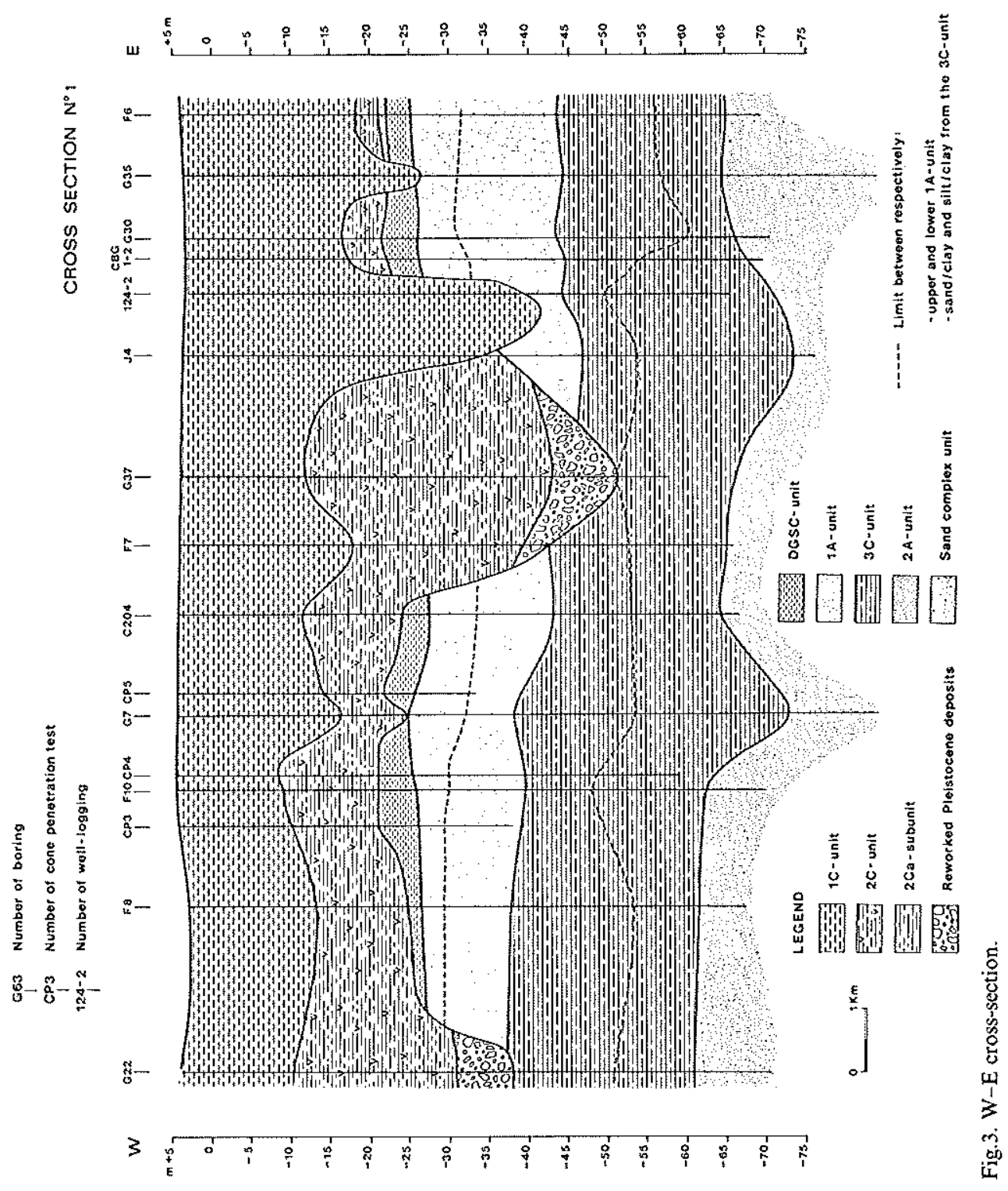




\section{GEOTECHNICAL TESTS}

\section{Laboratory tests}

Various laboratory tests have been performed (Dassargues et al., 1989) including about 450 current identification tests on disturbed and undisturbed samples with measurement of moisture content, Atterberg limits, dry unit weight and percentage of particle size diameter lower than 0.005 and $0.002 \mathrm{~mm}$.

The porosity $(n)$, void ratio $(e)$ and submerged unit weight $(\gamma)$ were determined assuming the value of the unit weight of solids $\left(\gamma_{\mathrm{s}}=2.7 \mathrm{~g} / \mathrm{cm}^{3}=25.48 \mathrm{kN} / \mathrm{m}^{3}\right)$ (see also the Notation).

\section{Plasticity characteristics}

On the basis of Atterberg limits, the plasticity diagrams are plotted for the different geological units distinguished by the Quaternary analysis (Fig.4). For each main unit, linear regression gives the following results:

\section{Notation}

\begin{tabular}{|c|c|}
\hline$n$ & Porosity \\
\hline$e$ & Void-ratio \\
\hline 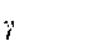 & Submerged unit weight \\
\hline$\gamma_{s}$ & Unit weight of solid \\
\hline$\ddot{\gamma}_{\mathrm{w}}=\rho g$ & Unit weight of water \\
\hline$I_{\mathrm{p}}$ & Plasticity index \\
\hline$w_{\mathrm{L}}$ & Liquid limil \\
\hline$c$ & Cohesion \\
\hline$\phi$ & Angle of internal friction \\
\hline$C_{\mathrm{c}}$ & Compression index \\
\hline$C_{\mathrm{s}}$ & Swelling index \\
\hline$C_{\mathrm{V}}$ & Consolidation coefficient \\
\hline$K^{\cdot}$ & Permeability coefficient $(\mathrm{m} / \mathrm{s})$ \\
\hline$k$ & Permeability coefficient $(\mathrm{cm} / \mathrm{s})$ \\
\hline$Q_{c}$ & Cone resistance \\
\hline$S_{\mathrm{s}}$ & Specific storage \\
\hline$\alpha_{N}, \beta_{N}$ & Coefficients of the transformed Nishida relation \\
\hline$\beta$ & Compressibility coefficient of the liquid \\
\hline$\beta_{\mathrm{s}}$ & Compressibility coefficient of the solid \\
\hline$x$ & Compressibility of the porous media \\
\hline$A$ & Swelling constant \\
\hline$C$ & Compression constant \\
\hline$\sigma^{\prime}$ & Effective stress \\
\hline$\sigma_{\text {prec }}^{\prime}$ & Preconsolidation effective stress \\
\hline$\sigma_{\mathbf{i}}^{\prime}$ & Initial effective stress in 1920 \\
\hline$f$ & Quantity of water expelled during consolidation \\
\hline$p$ & Water pressure \\
\hline$\varepsilon$ & Strain \\
\hline$H$ & Depth \\
\hline$e_{1}$ & Initial void ratio in 1920 \\
\hline$\varepsilon_{0}$ & Void ratio determined on samples taken after 1960 \\
\hline$\Delta e$ & Void ratio difference between the value of 1920 and the value at the sampling date \\
\hline
\end{tabular}



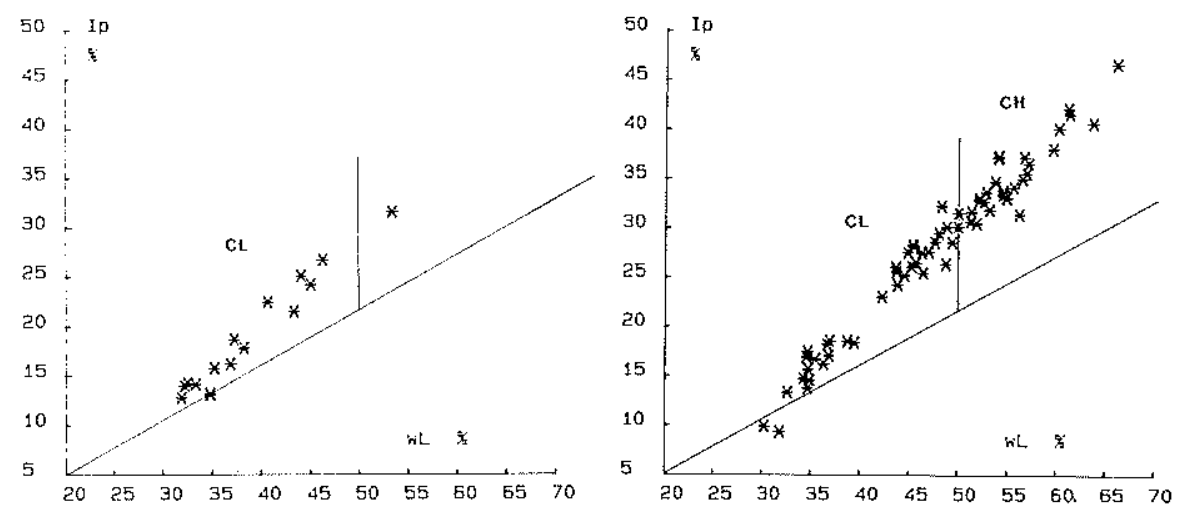

2ND COMPRESSIBLE LAYER

D.G.S.C. LAYER
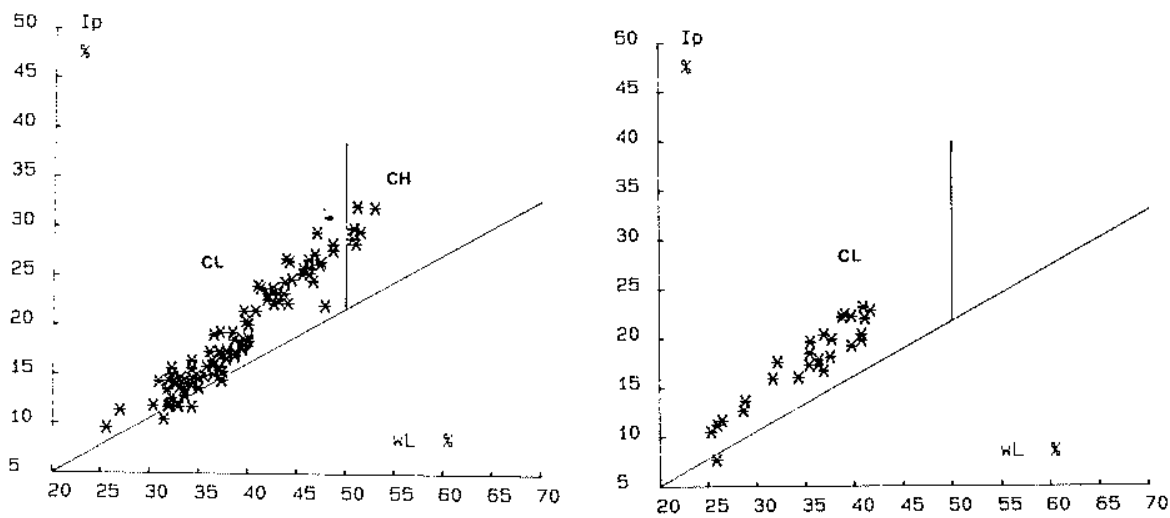

3RD COMPRESSIBLE LAYER

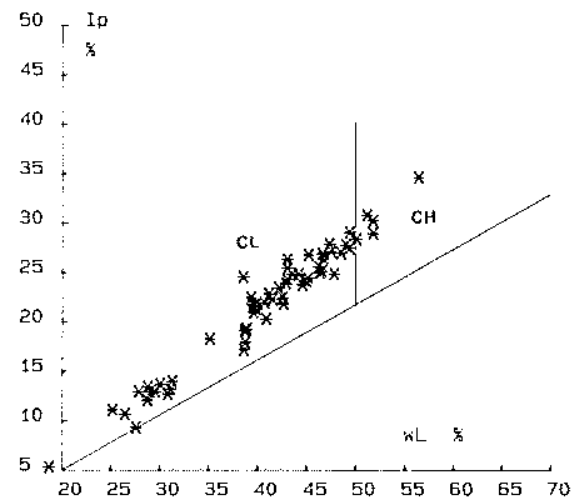

Fig.4. Plasticity diagrams. 
Superficial clay

First compressible layer

Second compressible layer

D.G.S.C. layer

Third compressible layer

$$
\begin{array}{ll}
I_{\mathrm{P}}=0.91 & \left(w_{\mathrm{L}}-18.08\right) \\
I_{\mathrm{P}}=0.63 & \left(w_{\mathrm{L}}-9.38\right) \\
I_{\mathrm{P}}=0.75 & \left(w_{\mathrm{L}}-16.49\right) \\
I_{\mathrm{P}}=0.53 & \left(w_{\mathrm{L}}-6.04\right) \\
I_{\mathrm{P}}=0.57 & \left(w_{\mathrm{L}}-7.79\right) .
\end{array}
$$

According to the USCS classification, the majority of the samples may be qualified $\mathrm{CL}(\mathrm{CL}=$ clay of low plasticity), but $\mathrm{CH}(\mathrm{CH}=$ clay of high plasticity) is also distinguished in the first compressible layer.

\section{Particle size distribution and water content}

The percentage of clay or silt particles of a size less than $0.005 \mathrm{~mm}$ gives an additional information for the identification. The comparison of the particle size distribution and the plasticity of the different layers can be done using histograms which show the frequency of samples classified in each class of content in a particle size less than $0.005 \mathrm{~mm}$ (Fig.5) and the frequency of the samples classified on basis of the water content (Fig.6). The higher plasticity of the first compressible layer is confirmed.

\section{Strength tests}

The soil strength is usually defined by the determination of the two parameters $c$ and $\phi$ issued from the Mohr-Coulomb criterion. Expressed in total stress, this criterion is written as:

$$
\tau=c+\sigma \operatorname{tg} \phi
$$

where $c=$ cohesion, $\phi=$ angle of internal friction, $\sigma=$ compressional stress, and $\tau=$ shear stress.

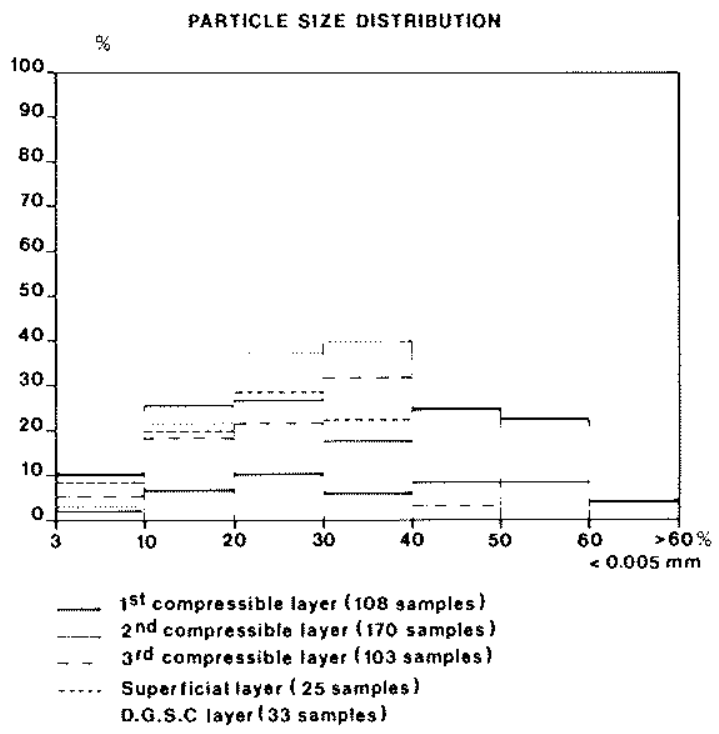

Fig.5. Histogram of the particle size distribution. 


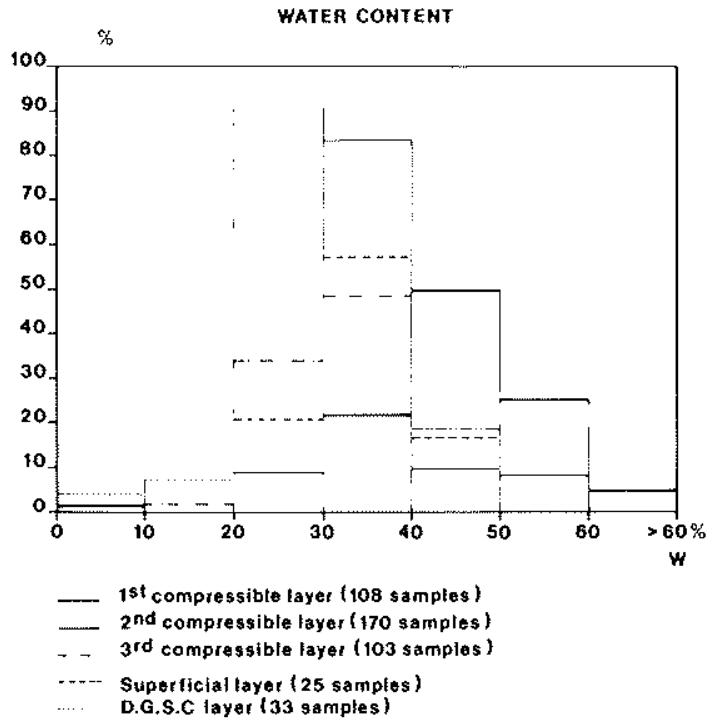

Fig.6. Histogram of the water content.

The Mohr-Coulomb failure envelopes have been deduced from isotropically consolidated undrained (C.I.U.C) triaxial compression tests on undisturbed samples (taken with a double core barrel) from the different layers (Fig.7).

The Fig. 8 shows the shear resistance (determined in a shear-box) plotted versus depth.

The results indicate: (1) that the DGSC layer is stronger, possesses some cohesion and a higher shear resistance (some points between -28 and $-43 \mathrm{~m}$ ); (2) that the phreatic aquifer represented by a few (probably disturbed) samples has no cohesion; this fact is of course in agreement with its sandy silty lithology; (3) that the first compressible layer (mainly between -10 and $-20 \mathrm{~m}$ ) is less resistant; this establishment is in agreement with its determined high plasticity and its clayey lithology.

\section{Compressibility}

Various incremental loading oedometer tests have been performed on undisturbed samples from each clayey layer. Low-pressure tests (with loading steps at 5, 78, 152, 299,594 and $1182 \mathrm{kN} / \mathrm{m}^{2}$ ), and high-pressure tests (with loading steps at 1500, 2500, 5000,7500 and $10000 \mathrm{kN} / \mathrm{m}^{2}$ ), have provided more than 500 values of the compressibility parameters. The preconsolidation effective stress $\left(\sigma_{\text {prec }}^{\prime}\right)$ has been determined applying the Casagrande construction. The compression index $C_{\mathrm{c}}$, the consolidation coefficient $C_{v}$ and the permeability $K$ have been calculated for each loading step.

As an example, we can provide the $C_{\mathrm{c}}$ and the $\sigma_{\text {prec }}^{\prime}$ values for the different layers:

Phreatic aquifer $0.04 \leq C_{\mathrm{c}} \leq 0.09$

First compressible layer $0.4 \leq C_{\mathrm{c}} \leq 1.2 \quad\left(20 \leq \sigma_{\text {prec }}^{\prime} \leq 180 \mathrm{kPa}\right)$

Second compressible layer

$0.3 \leq C_{\mathrm{c}} \leq 1.2 \quad\left(110 \leq \sigma_{\text {prec }}^{\prime} \leq 310 \mathrm{kPa}\right)$ 

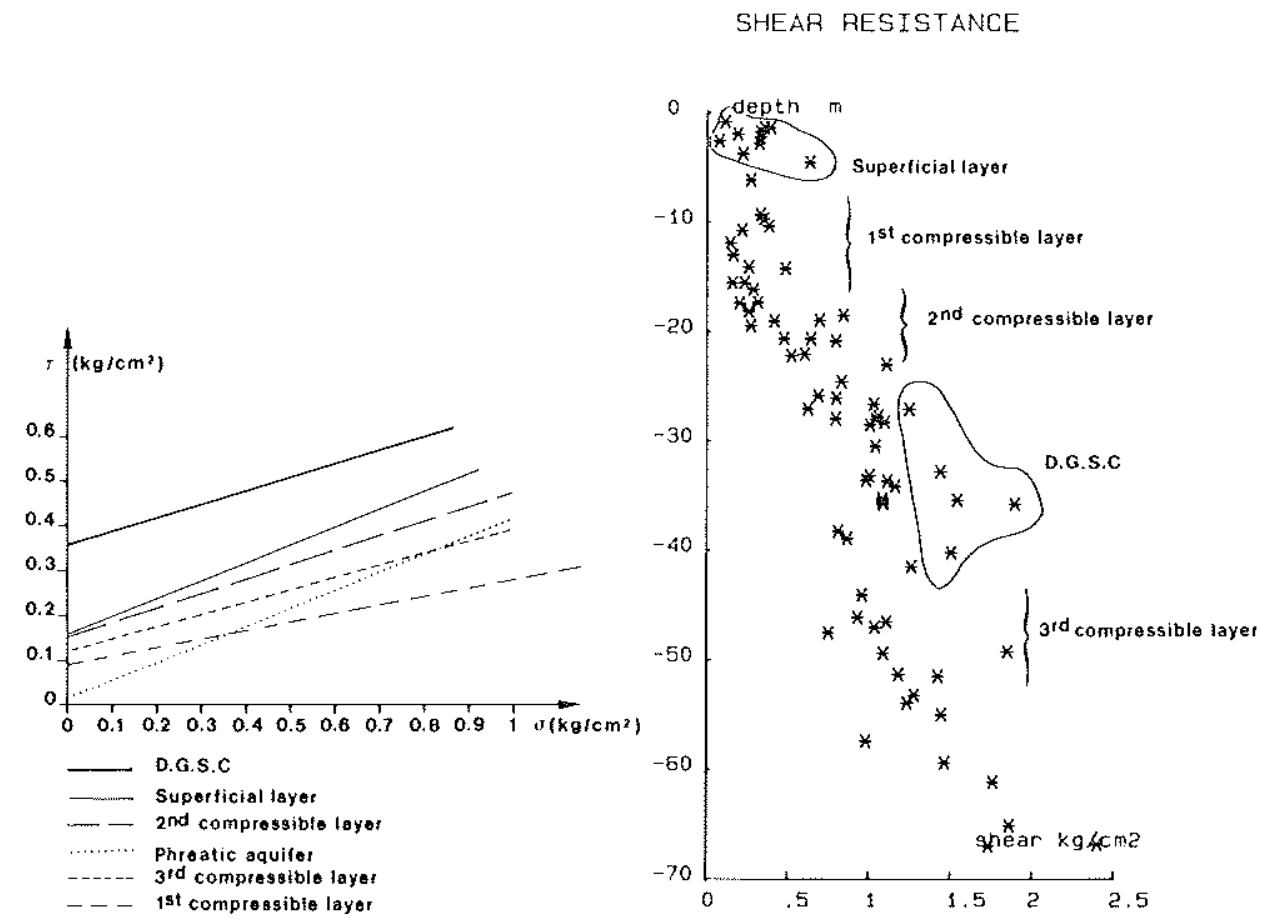

Fig.7. Mohr-Coulomb diagram and shear resistance distribution.
D.G.S.C. layer
$0.2 \leq C_{\mathrm{c}} \leq 0.4 \quad\left(350 \leq \sigma_{\text {prec }}^{\prime} \leq 630 \mathrm{kPa}\right)$
First aquifer
$0.2 \leq C_{\mathrm{c}} \leq 0.3 \quad\left(310 \leq \sigma_{\text {prec }}^{\prime} \leq 420 \mathrm{kPa}\right)$
Third compressible layer
$0.3 \leq C_{\mathrm{c}} \leq 0.5 \quad\left(300 \leq \sigma_{\text {prec }}^{\prime} \leq 450 \mathrm{kPa}\right)$
Second aquifer
$0.15 \leq C_{\mathrm{c}} \leq 0.2 \quad\left(360 \leq \sigma_{\mathrm{prec}}^{\prime} \leq 580 \mathrm{kPa}\right)$

$C_{\mathrm{c}}$ is considered as independant of the value of $e_{0}$. The influence of $e_{0}$ on the compaction can be expressed by:

$$
C=2.3\left(1+e_{0}\right) / C_{c}
$$

where $C$ is the compression constant determined on the oedometric semi-log diagram $\left(\ln \sigma^{\prime}, \varepsilon\right)$.

\section{$X$-ray analysis}

Detailed qualitative and quantitative analysis by $X$-ray difraction have been conducted (by Prof. Thorez) on more than 50 samples.

Thirteen different clay minerals (simple and mixed layers) have been identified: illites, chlorite, smectites, vermiculite, kaolinite (for the simple clay mineral components) and various mixed layers: $\left(10-14_{\mathrm{Sm}}\right),\left(10-14_{\mathrm{C}}\right),\left(10-14_{\mathrm{Be}}\right) 17 \mathrm{~A}, \mathrm{Al}_{17},\left(14_{\mathrm{C}}-14_{\mathrm{V}}\right)$.

Their identification has been completed through the cationic saturations associated with subsequent treatments (heatings, solvation with either ethylene or glycerol vapors).

The illite component has been differentiated between illite with sharp peak, enlarged peak and open illite (with distended interlayers). Moreover the octahedral 


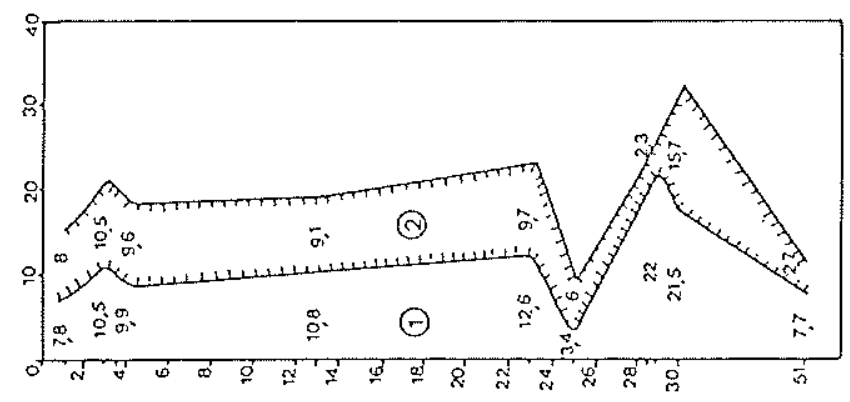

营芜
$\stackrel{\infty}{\infty}$
$\stackrel{0}{2}$

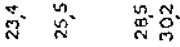

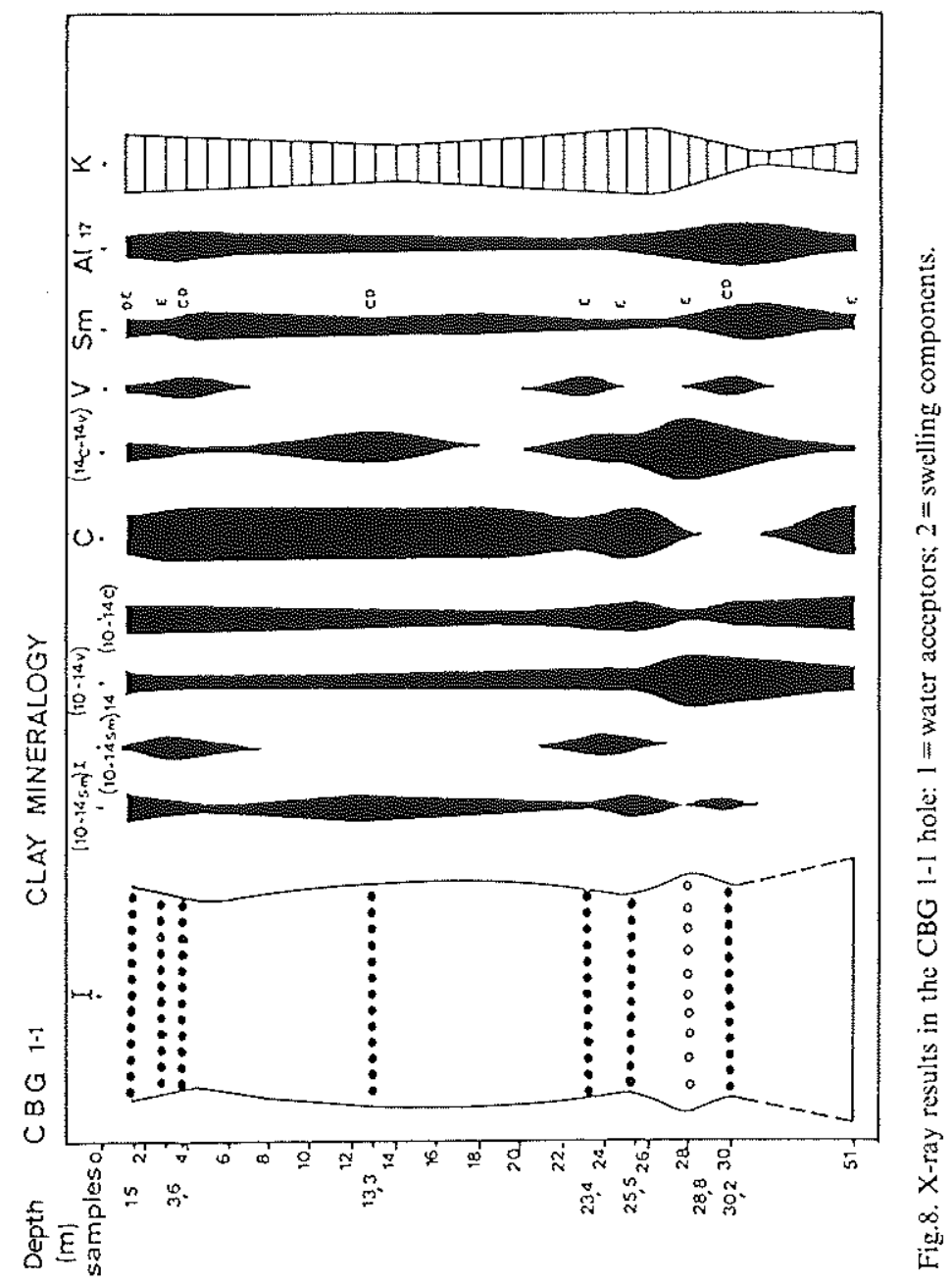


$\mathrm{Al} /(\mathrm{Fe}+\mathrm{Mg})$ composition of the illite population was calculated according to the Esquevin's method.

The smectites were differentiated between beidellite, montmorillonite and a mixed layer component $\left(10-14_{\mathrm{Be}}\right) 17 \mathrm{~A}$, composed of residual illitic layers and predominant swelling (beidellite) layers. The distribution of the smectitic particles was provided by "Bisxaye" ratio V/p. The real amount of swelling layers within the smectite was calculated.

A corrected percentage of the different clay components has been provided for the complex clay admixtures, with an accuracy of $+1-15 \%$.

Several intensity ratios have been calculated, allowing to differentiate the trends supported by specific clay components independently of the overall clay assemblage.

Graphic presentation as Fig. 8 provides a direct visualization of the sensitive lithological formations.

Illite and kaolinite are the dominant clay components. Beside them, the complex clay association is such that no clear cut or evolution can be traced. The trends in occurrences of water accepters (1) and swelling components (2) are to be linked to the compressibility of the sediment under drained consolidation. This relation is apparent in Fig. 8 in the compressible layers.

\section{In-silu tests}

\section{C.P.T.}

Numerous mechanical Cone Penetration Tests $\left(60^{\circ}\right.$ apex and $36 \mathrm{~mm}$ diameter, type M4) have been performed. The interpretation gives the following values of $Q_{\mathrm{c}}$ (in $\mathrm{kg} / \mathrm{cm}^{2}$ ) (Fig.9):

Superficial layer

$$
7 \leq Q_{\mathrm{c}} \leq 20
$$

First compressible layer

and top of the second

$$
\begin{array}{ll}
\text { compressible layer } & 2 \leq Q_{\mathrm{c}} \leq 5 \\
\text { Lower second compressible } & \\
\text { layer } & 4.5 \leq Q_{\mathrm{c}} \leq 16 \\
\text { DGSC layer } & 15 \leq Q_{\mathrm{c}} \leq 35 \\
\text { Third compressible layer } & 20 \leq Q_{\mathrm{c}} \leq 50 \\
\text { Second aquifer } & 100 \leq Q_{\mathrm{c}}
\end{array}
$$

The contrasts between the second aquifer and the compressible layers is particularly evident. This fact has helped in the accurate determination of the top of the second aquifer in many places. The evolution of the $Q_{\mathfrak{c}}$ value in function of the depth shows the same main trends as the evolution of the shear-resistance in the different layers (Fig.7).

\section{Well logging}

The usefulness of the gamma-ray, gamma-gamma and neutron-neutron measurements has been restricted to qualitative interpretation because no adequate calibration was possible in the logged holes.

However, all the informations have been used in the correlations and interpretations in order to define more clearly the complex geometry of the different 


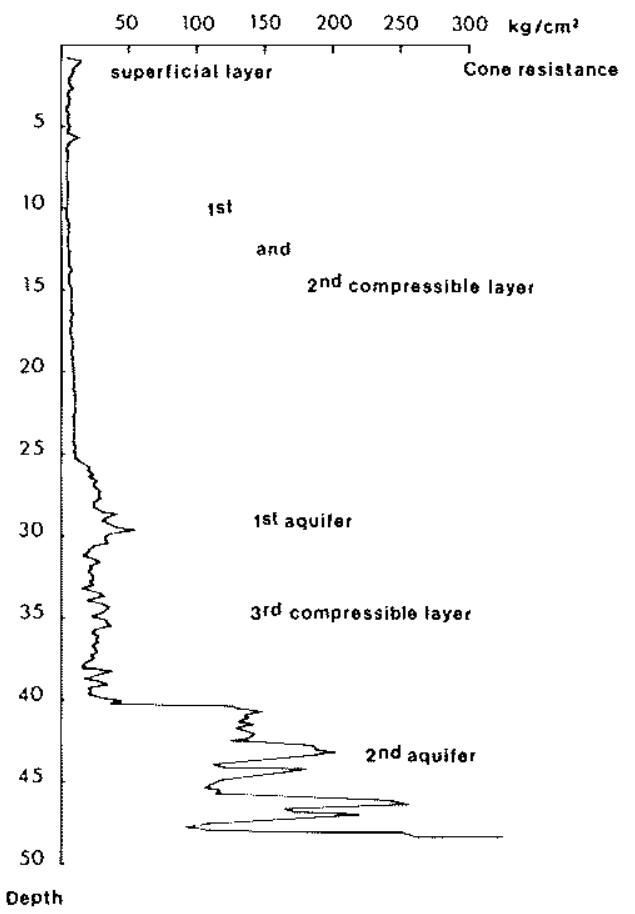

Fig.9. Cone Penetration Test.

formations. An example is given in Fig. 10, where it is to be noted that occurrence of gas in the second compressible layer is particularly visible in the neutron-neutron $\log$.

\section{Pumping-test}

Many pumping-tests have been performed in the second aquifer with piezometers situated in each layer including compressible (semi-pervious) layers.

The recorded decrease of pressure in the first aquifer, when pumping in the second aquifer, is more probably due to lateral propagation of the depression through the connection of these two aquifers, than to the conductance of the third compressible layer situated between them.

The ranges of variation of the calculated values of permeability and specific storage in the second aquifer are respectively:

$$
\begin{gathered}
1 \cdot 10^{-4} \leq K \leq 8.7 \cdot 10^{-4} \mathrm{~m} / \mathrm{s} \\
1 \cdot 10^{-6} \leq S_{\mathrm{s}} \leq 2 \cdot 10^{-5} \mathrm{~m}^{-1}
\end{gathered}
$$

\section{Variation of the parameters}

In soil consolidation problems, the compaction flow is described more realistically if specific storage $\left(S_{\mathrm{s}}\right)$ is coupled with a geomechanic parameter in the flowcompaction equation and if hydraulic conductivity $(K)$ can vary with effective stress 


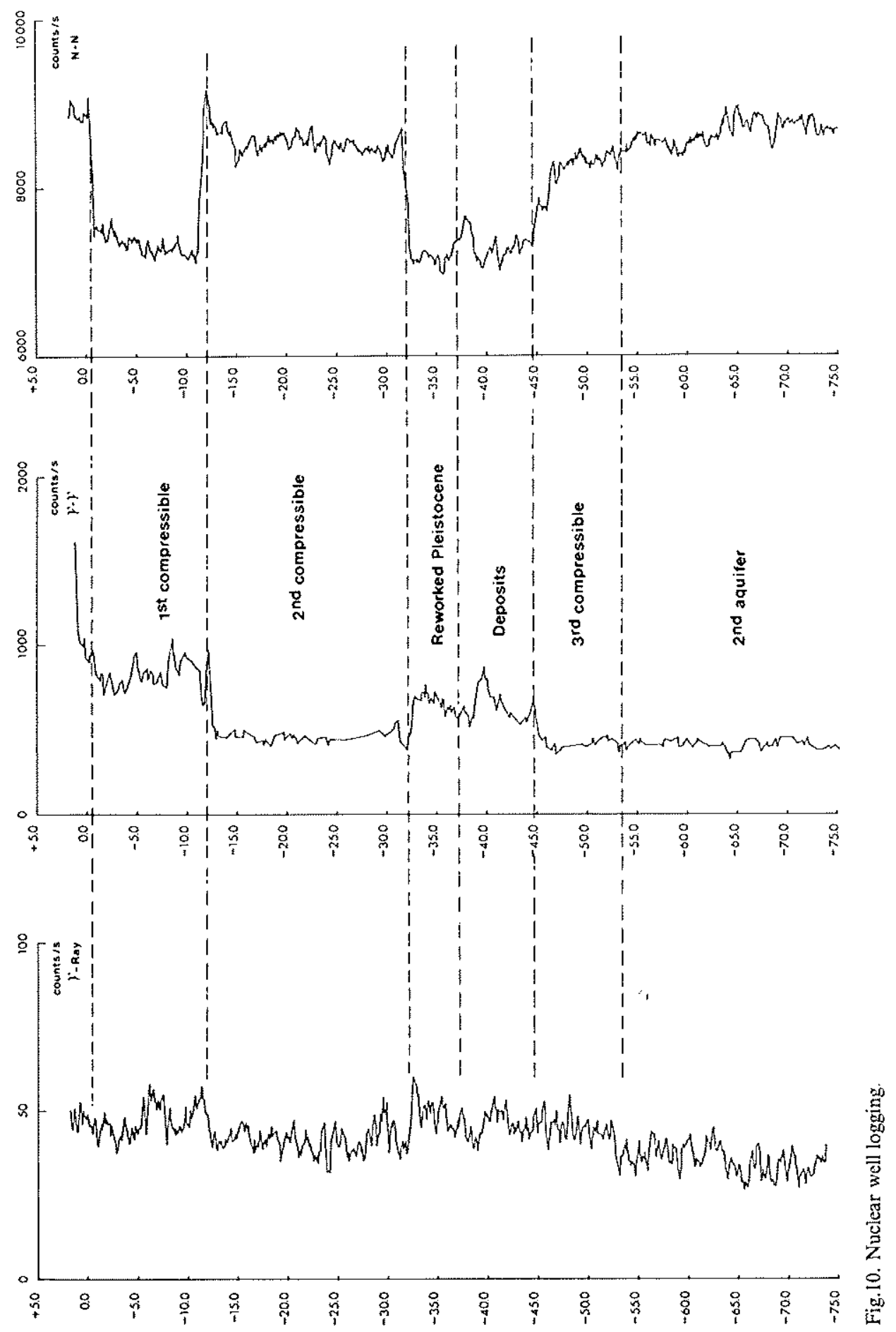


$\left(\sigma^{\prime}\right)$ (Bethke and Corbet, 1988). This variation introduces a non-linearity very important to take into account in the case of highly compressible layers.

Many relations linking $K$ (hydraulic conductivity) to the porosity (Main et al., 1963) are used, corresponding in each case to different lithological and geotechnical conditions (Mesri and Olson, 1971).

For Shanghai sediments, the best tested empirical relation is the equation of Nishida and Nakagawa (1969). Based on extensive experimental results on various estuarine, marine recent clays, the relation links the permeability $K$ to void ratio $e$ and plasticity index $I_{\mathrm{p}}$ :

$$
e=a+b \log _{10} k
$$

where:

$$
\begin{aligned}
& a=10 . \mathrm{b} \\
& b=0.01 I_{\mathrm{P}}+0.05
\end{aligned}
$$

and $k=$ permeability in $\mathrm{cm} / \mathrm{s}$.

If the permeability coefficient is expressed in $\mathrm{m} / \mathrm{s}$ and we enter the value of $a$ in eq. (2), we obtain:

$$
K=\exp \left(\alpha_{\mathrm{N}} \cdot e+\beta_{\mathrm{N}}\right)
$$

where:

$$
\alpha_{\mathrm{N}}=2.3 / \mathrm{b} \text { and } \beta_{\mathrm{N}}=-27.6
$$

The value of $\alpha_{\mathrm{N}}$ depends of $I_{\mathrm{P}}$ which characterizes each clayey layer. To obtain a realistic relation for each layer, the $b$ value is generalized by the following relation;

$$
b=C+D I_{\mathrm{P}}
$$

where $C$ and $D$ are constants adapted for each layer.

In the study area of Shanghai, the different tests have given permeability values (by oedometer tests), void ratio and plasticity index.

Diagrams of $I_{\mathrm{P}}(\%)$ versus $b$ are drawn for clayey layers and linear regressions led to the determination of $C$ and $D$ of eq. 7 :

$$
\begin{array}{ll}
\text { First compressible layer } & b=0.213+0.083 I_{\mathrm{P}} \\
\text { Second compressible layer } & b=0.0167+0.0174 I_{\mathrm{P}} \\
\text { DGSC layer } & b=0.0885+0.0127 I_{\mathrm{P}} \\
\text { Third compressible layer } & b=0.176+0.079 I_{\mathrm{P}}
\end{array}
$$

The variation of specific storage $S_{\mathrm{s}}$ during an oedometer test is clearly shown in Fig.11. The more general expression for the specific storage (Bredehoeft and Cooley, 1983) is:

$$
S_{\mathrm{s}}=\rho g n\left(\beta-\beta_{\mathrm{s}}+\frac{\alpha}{n}\right)
$$

where $\rho \mathrm{g}=\gamma_{\mathrm{w}}=$ unit weight of the liquid, $\beta=$ compressibility coefficient of the liquid, $\beta_{\mathrm{s}}=$ compressibility coefficient of the solid, $\alpha=$ compressibility of the porous media due to the decrease of porosity. 


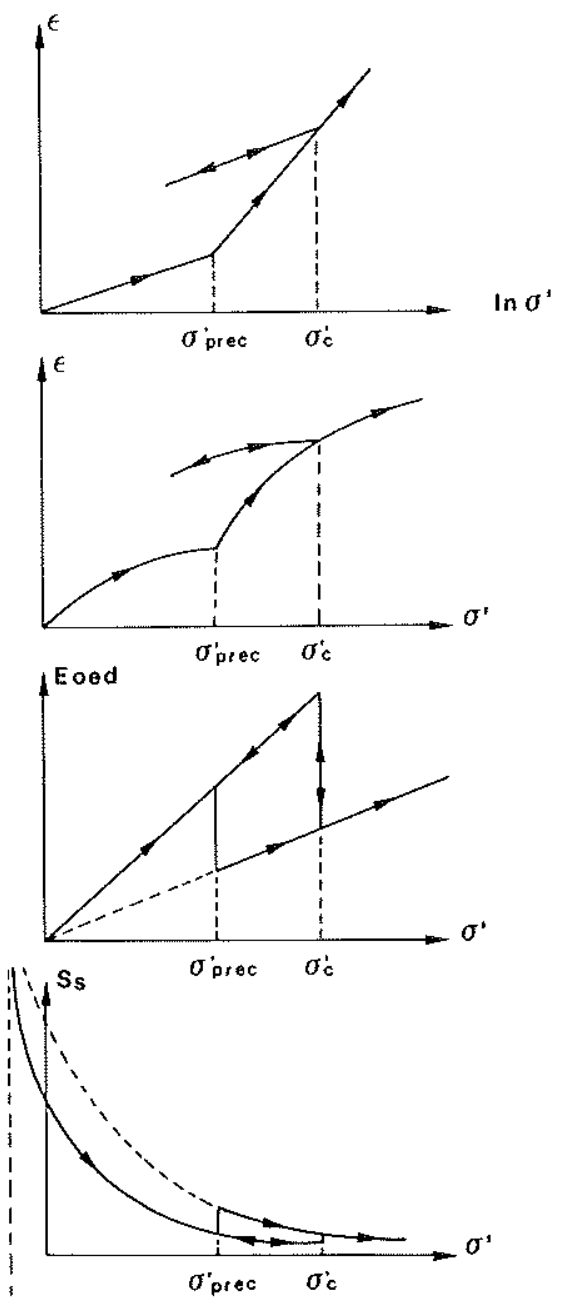

Fig.11. Variation of the specific storage during oedometer loading.

Usually $\beta$ and $\beta_{\mathrm{s}}$ are neglected in front of $\alpha$, and $S_{\mathrm{s}}$ is expressed in function of oedometer constants:

$$
\begin{aligned}
& S_{\mathrm{s}}=\gamma_{\mathrm{w}} / A \sigma^{\prime} \text { in elastic part } \\
& S_{\mathrm{s}}=\gamma_{\mathrm{w}} / C \sigma^{\prime} \text { in plastic part }
\end{aligned}
$$

where $A=$ swelling constant, and $C=$ compression constant.

As it is illustrated in Fig.11, there is a continuous variation of $S_{\mathrm{s}}$ (depending of the effective stress $\sigma^{\prime}$ ), added to a discontinuity corresponding to the effective preconsolidation stress.

In our coupled flow-compaction constitutive law, this variation will be auto- 
matically taken into account assuming that the total quantity of water expelled during compaction $\left(f^{*}\right)$ is equal to the time variation of the strain:

$$
f^{v}=S_{\mathrm{s}} \frac{\dot{p}}{\gamma_{\mathrm{w}}}=-S_{\mathrm{s}} \frac{\dot{\sigma}^{\prime}}{\gamma_{\mathrm{w}}}=-\dot{\varepsilon}
$$

where $p=$ water pressure, and $\varepsilon=$ strain.

This eq. (11) can be written only if Terzaghi's relation and constant total stress are assumed (Terzaghi and Peck, 1948).

Replacing $S_{\mathrm{s}}$ by its value in function of the oedometer constants (eqs. 9 and 10), this relation is equivalent to the oedometer law:

$$
\begin{aligned}
& \dot{\sigma}^{\prime}=A \sigma^{\prime} \dot{\varepsilon} \text { if } \sigma^{\prime} \leq \sigma_{\text {prec }}^{\prime} \text { (elastic part) } \\
& \dot{\sigma}^{\prime}=C \sigma^{\prime} \dot{\varepsilon} \text { if } \sigma^{\prime} \geq \sigma_{\text {prec }}^{\prime} \text { (plastic part) }
\end{aligned}
$$

For the compressible layers, the values of the effective preconsolidation are determined by the oedometer tests completed between 1960 and 1985. The results have shown that the first, second and third compressible layers are very slightly overconsolidated and the DGSC layer highly overconsolidated. This overconsolidation of the compressible layers is probably due to the consolidation which has occurred between 1920 and 1965 (during the main subsidence). To obtain realistic initial conditions for the numerical simulation, we had to assume an equilibrium triangular distribution of the initial effective stress $\left(\sigma_{i}^{\prime}\right)$ in 1920 , corresponding to saturated layers until the surface.

The preconsolidation effective stress is everywhere assumed equal to the initial effective stress, except in the DGSC layer, which is considered overconsolidated in 1920 with a mean ratio:

$$
\sigma_{\text {prec }}^{\prime} / \sigma_{\mathrm{i}}^{\prime}=1.4
$$

For aquifers and compressible layers, we assume:

$$
\sigma_{\mathrm{prec}}^{\prime}=\sigma_{i}^{\prime}=\left(\gamma-\gamma_{\mathrm{w}}\right) H
$$

where $H=$ depth, $\sigma_{\mathrm{i}}^{\prime}=$ initial effective stress (1920), and $\gamma=$ bulk density.

For computation of the subsidence, the values of $A$ and $C$ are determined from $C_{\mathrm{s}}$, $C_{\mathrm{c}}$ and initial void ratio of $1920\left(e_{\mathrm{i}}\right)$ by:

$$
\begin{aligned}
& A=2.3\left(1+e_{\mathrm{i}}\right) / C_{\mathrm{s}} \\
& C=2.3\left(1+e_{\mathrm{i}}\right) / C_{\mathrm{c}}
\end{aligned}
$$

The initial void ratio is deduced from the relation:

$$
e_{\mathrm{i}}=\Delta e+e_{0}
$$

where $e_{0}=$ void ratio determined by the geotechnical tests on the samples, and $\Delta e=$ variation of the void ratio between 1920 and the sampling date.

In the case of normally consolidated layers (first, second and third compressibles; first and second aquifers) $\Delta e$ is determined by:

$$
\Delta e=C_{\mathrm{c}} \log \frac{\sigma_{\mathrm{i}}^{\prime}+\Delta \sigma^{\prime}}{\sigma_{\mathrm{i}}^{\prime}} \text { (only plastic part) }
$$




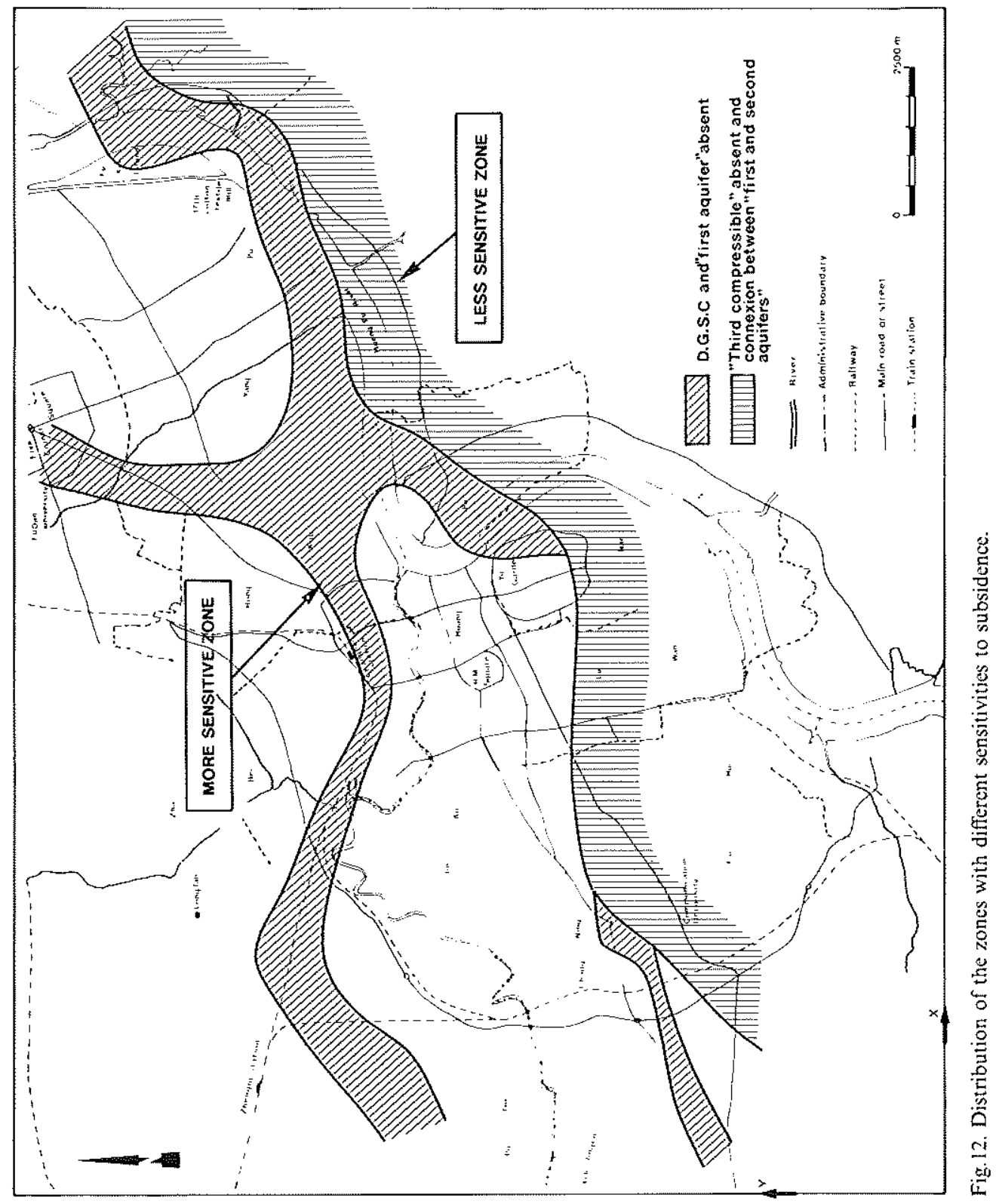


In the case of the DGSC layer:

$$
\begin{aligned}
& \Delta e=C_{\mathrm{s}} \log \frac{\left(\sigma_{\mathrm{i}}^{\prime}+\Delta \sigma^{\prime}\right)}{\sigma_{\mathrm{i}}^{\prime}} \quad \text { (only elastic part) } \\
& \text { if } \Delta \sigma^{\prime} \leq\left(\sigma_{\text {prec }}^{\prime}-\sigma_{\mathrm{i}}^{\prime}\right) \\
& \Delta e=C_{\mathrm{s}} \log \frac{\sigma_{\text {prec }}^{\prime}}{\sigma_{\mathrm{i}}^{\prime}}+C_{\mathrm{c}} \log \frac{\sigma_{\mathrm{i}}^{\prime}+\Delta \sigma^{\prime}}{\sigma_{\text {prec }}^{\prime}} \quad \text { (elastic and plastic parts) }
\end{aligned}
$$

Entering the values of $\Delta e$ in relation 18 , and the values of $e_{\mathrm{i}}$ in relations 16 and 17 , we have obtained the compressibility parameters $A$ and $C$.

\section{CONCLUSIONS}

Before computations of the land subsidence by a mathematical model, some main facts about the characteristics of the Holocene and Upper Pleistocene sediments of the Shanghai central area can be pointed out.

The main subdivisions are issued from the lithological Quaternary analysis and are fully confirmed and detailed by the results of the engineering geology and geotechnical tests.

For the different units of the sequence, the hydrogeology and engineering geology parameters have been obtained as they are necessary for the computation of the subsidence.

It appears that variable sedimentological conditions have led to a geometrically complex distribution of the different units. This distribution influences the value of the compaction in the different zones. For example, the lack of the DGSC layer and/or the first aquifer will increase theoretically the value of the subsidence in the zone concerned. On the contrary, the connection of the first and second aquifer with in this case the third compressible missing, and the occurrence in some places of a phreatic aquifer in relation with the "Huang Pu River" but included in the first compressible layer, will decrease the value of the subsidence in these zones. Of course, the variable relative thicknesses of the compressible layers and their eventual organic content will also influence greatly the subsidence phenomena.

On the basis of these conclusions a map can be drawn representing the zones more sensitive to subsidence phenomena (Fig.12).

\section{ACKNOWLEDGEMENTS}

This work has been carried out under an International Cooperation Agreement between the Ministry of Geology and Mineral Resources of the People's Republic of China and the Services of Scientific Policy and Planning of the Prime Minister of Belgium. The authors are grateful to the Chinese engineers of the Shanghai Geological Bureau for their participation in the works and discussions during the whole study. Thanks must also be expressed to Mrs Baeteman of the Belgian Geological Survey for the detailed Quaternary analysis. 


\section{REFERENCES}

Baeteman, C., 1989. The Upper Quaternary Deposits of the Changjiang Coastal Plain (Shanghai Area). Belgian Geological Survey. Unpublished.

Bethke, C.M. and Corbet, T.F., 1988. Linear and non-linear solutions for one-dimensional compaction flow in sedimentary basins. Water Resour. Res., 24(3): 461-467.

Bredehoeft, J.D. and Cooley, R.L., 1983. Comment on "A note on the meaning of storage coefficient" by T.N. Narasimhan and B.Y. Kanehiro. Water Resour. Res., 19(6): 1632-1634.

Dassargues, A., Schroeder, Ch. and Monjoie, A., 1989. The Hydrogeology and Engineering Geology of the Shanghai Area. Laboratoires de Géologie de I'Ingénieur, d'Hydrogéologie et de Prospection géophysique, Report SPPS 891 . Unpublished.

De Waal, J.A. and Smits, R.M.M., 1985. Prediction of Reservoir Compaction and Surface Subsidence: Field Application of a New Model. Society of Petroleum Engineers. Pap. SPE14214, Annu. Tech. Conf. Exhib. SPE, 60th (Las Vegas).

Main, R., Chilingar, G.V. and Sinnokrat, A., 1963. Relationship between porosity, permeability and surface area of sediments. J. Sediment. Petrol, 33(3): 759-765.

Mesri, M. and Olson, R.E., 1971. Mechanisms controlling the permeability of clays. Clays Clay Miner., 19: $151-158$.

Nishida, Y. and Nakagawa, S., 1969. Water permeability and plastic index of soils In: Land Subsidence IAHS-UNESCO, Publ. 89, AIHS (2), pp.573-578.

Rieke, M.M., and Chilingarian, G.V., 1974. Compaction of Argillaceous Sediments. Elsevier, Amsterdam.

Terzaghi, K. and Peck, R., 1948. Soil Mechanics in Engineering Practice. Wiley, New York, N.Y.

Vidalie, J.F., 1977. Relations entres les propriétés physico-chimiques et les caractéristiques mécaniques des sols compressibles. Rapport de Recherche LPC, 65. 